\title{
Using and \\ Understanding \\ Medical \\ Statistics
}




\section{David E. Matthews · Vernon T. Farewell}

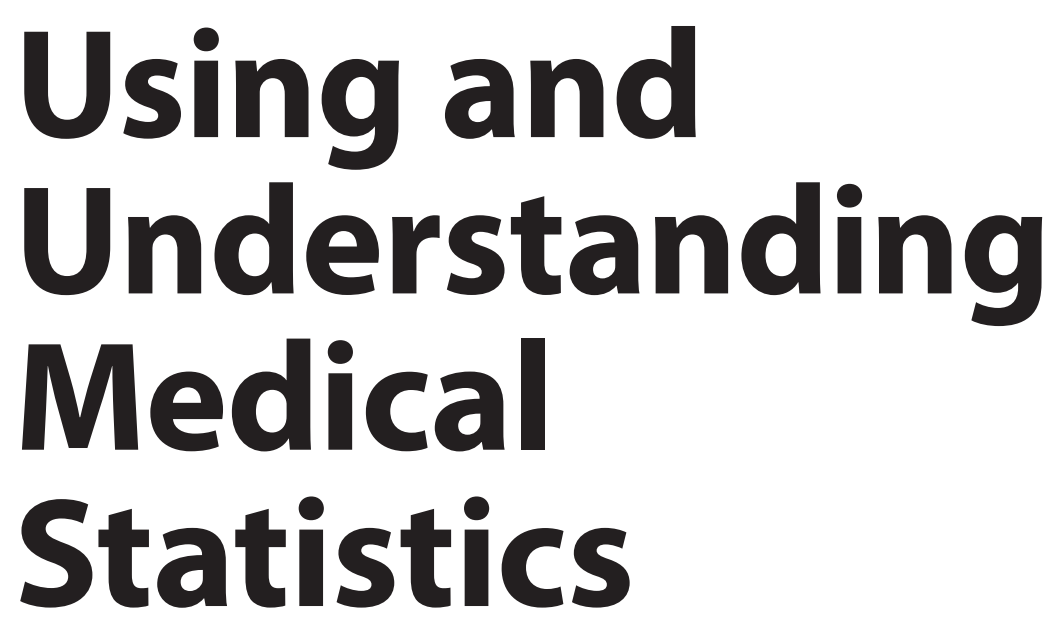

4th, completely revised and enlarged edition

42 figures and 113 tables, 2007

KARGR Basel $\cdot$ Freiburg $\cdot$ Paris $\cdot$ London $\cdot$ New York •

Bangalore $\cdot$ Bangkok $\cdot$ Singapore $\cdot$ Tokyo $\cdot$ Sydney 


\title{
David Edward Matthews
}

\author{
BA, MA (Western Ontario), PhD (London); \\ Professor, Department of Statistics and Actuarial Science, \\ University of Waterloo, Waterloo, Ontario, Canada
}

\section{Vernon Todd Farewell}

\author{
B. Math, M. Math (Waterloo), PhD (London); Senior Scientist \\ MRC Biostatistics Unit, Cambridge, UK
}

Library of Congress Cataloging-in-Publication Data

Matthews, David E., 1948-

Using and understanding medical statistics / David E. Matthews Vernon T.

Farewell. - 4th, completely rev. and enl. ed.

p. ; $\mathrm{cm}$.

Includes bibliographical references and index.

ISBN-13: 978-3-8055-8189-9 (hard cover : alk. paper)

ISBN-10: 3-8055-8189-0 (hard cover : alk. paper)

1. Medical statistics. I. Farewell, Vernon T. II. Title.

[DNLM: 1. Biometry-methods. 2. Statistics. WA 950 M438u 2007]

RA409.M39 2007

610.1 '5195-dc22

2006100514

Bibliographic Indices. This publication is listed in bibliograpahic services, including Current Contents ${ }^{\circledR}$ and Index Medicus.

Disclaimer. The statements, options and data contained in this publication are solely those of the individual authors and contributors and not of the publisher and the editor(s). The appearance of advertisements in the book is not a warranty, endorsement, or approval of the products or services advertised or of their effectiveness, quality or safety. The publisher and the editor(s) disclaim responsibility for any injury to persons or property resulting from any ideas, methods, instructions or products referred to in the content or advertisements.

Drug Dosage. The authors and the publisher have exerted every effort to ensure that drug selection and dosage set forth in this text are in accord with current recommendations and practice at the time of publication. However, in view of ongoing research, changes in government regulations, and the constant flow of information relating to drug therapy and drug reactions, the reader is urged to check the package insert for each drug for any change in indications and dosage and for added warnings and precautions. This is particularly important when the recommended agent is a new and/or infrequently employed drug.

All rights reserved. No part of this publication may be translated into other languages, reproduced or utilized in any form or by any means, electronic or mechanical, including photocopying, recording, microcopying, or by any information storage and retrieval system, without permission in writing from the publisher.

() Copyright 2007 by S. Karger AG, P.O. Box, CH-4009 Basel (Switzerland)

www.karger.com

Printed in Switzerland on acid-free paper by Reinhardt Druck, Basel

ISBN-13: 978-3-8055-8189-9 (hard cover : alk. paper), ISBN-10: 3-8055-8189-0 (hard cover : alk. paper) 
To Nancy and Jane 


\section{Contents}

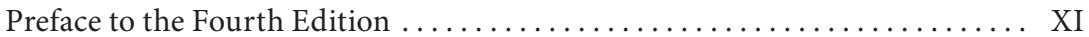

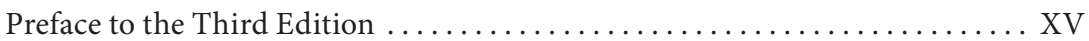

Preface to the Second Edition ...................................

Preface to the First Edition $\ldots \ldots \ldots \ldots \ldots \ldots \ldots \ldots \ldots \ldots \ldots \ldots \ldots \ldots \ldots \ldots \ldots$ XIX

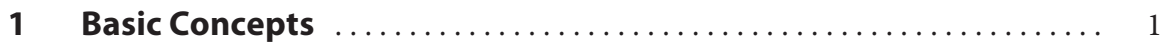

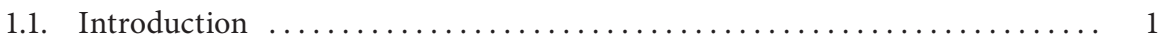

1.2. Random Variables, Probability Distributions and Some Standard Notation .. 2

1.3. Characteristics of a Distribution: Mean, Median and Variance ........... 8

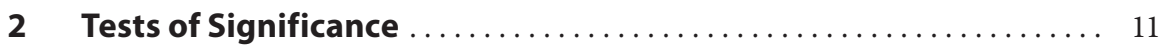

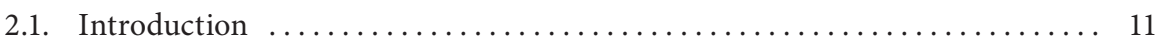

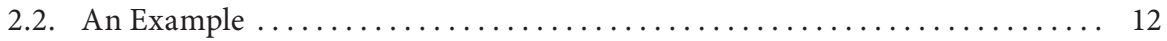

2.3. Common Features of Significance Tests ...................... 17

3 Fisher's Test for $\mathbf{2} \times \mathbf{2}$ Contingency Tables .................. 19

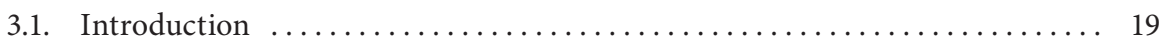

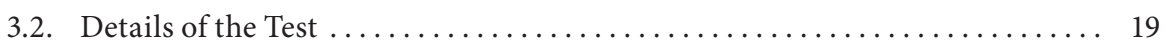

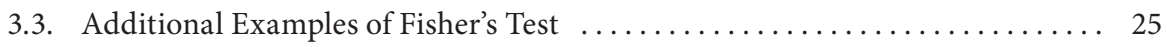

4 Approximate Significance Tests for Contingency Tables ....... 28

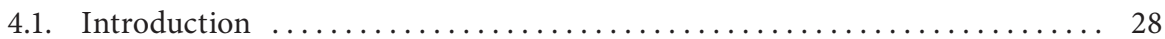

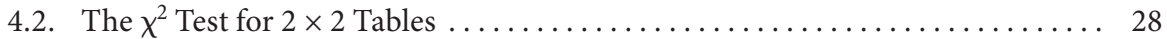

4.3. The $\chi^{2}$ Test for Rectangular Contingency Tables .................. 35

4.4. Using Statistical Tables of the $\chi^{2}$ Probability Distribution $\ldots \ldots \ldots \ldots \ldots . \ldots 42$

5 Some Warnings Concerning $2 \times 2$ Tables $\ldots \ldots \ldots \ldots \ldots \ldots$

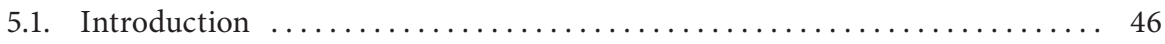

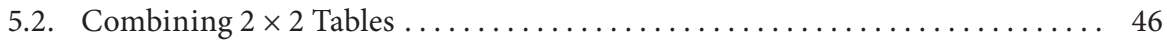

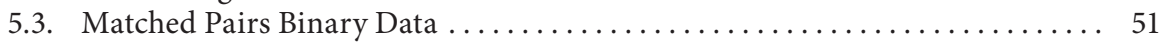


6 Kaplan-Meier or 'Actuarial' Survival Curves ............... 54

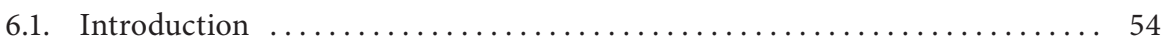

6.2. General Features of the Kaplan-Meier Estimate . . . . . . . . . . . . . . 56

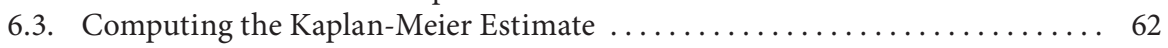

6.4. A Novel Use of the Kaplan-Meier Estimator .................... 64

\section{The Log-Rank or Mantel-Haenszel Test for the Comparison of}

Survival Curves ................................ 67

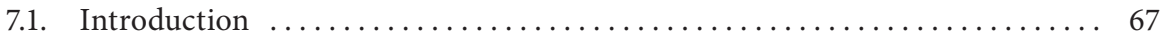

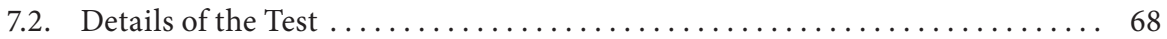

7.3. Evaluating the Log-Rank Test - A Simple Example ............... 71

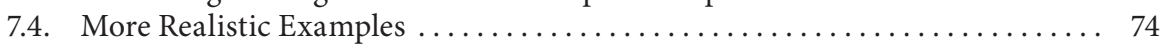

8 An Introduction to the Normal Distribution ............... 76

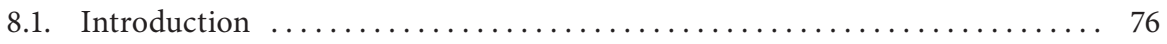

8.2. Basic Features of the Normal Distribution $\ldots \ldots \ldots \ldots \ldots \ldots \ldots \ldots \ldots \ldots$

8.3. The Normal Distribution and Significance Testing ................ 81

8.4. The Normal Distribution and Confidence Intervals ................ 84

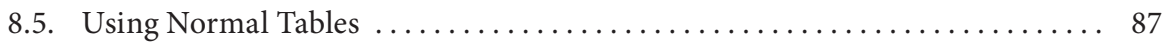

$9 \quad$ Analyzing Normally Distributed Data ................... 90

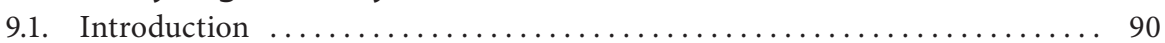

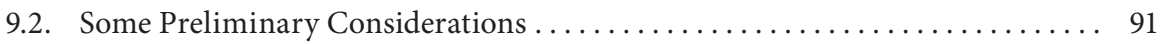

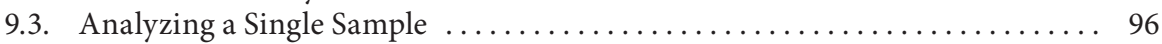

9.4. Comparisons Based on the Normal Distribution .................. 100

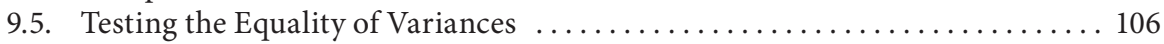

10 Linear Regression Models for Medical Data . . . . . . . . . . . . . 111

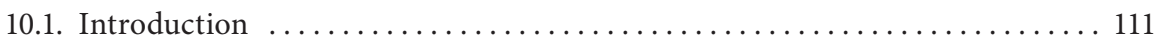

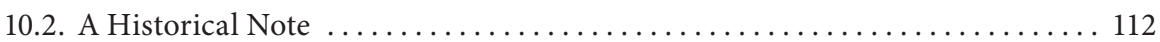

10.3. Multiple Linear Regression ............................... 113

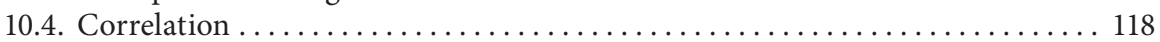

10.5. The Analysis of Variance . . . . . . . . . . . . . . . . . . . 122

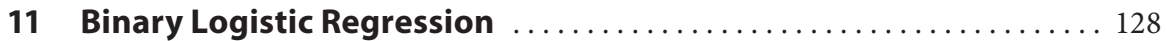

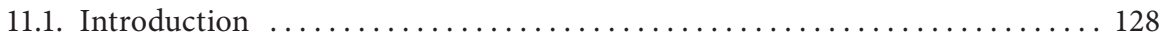

11.2. Logistic Regression ..................................... 129

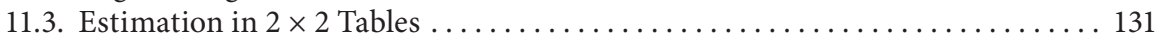

11.4. Reanalysis of a Previous Example ............................. 135

11.5. The Analysis of Dose-Response Data . . . . . . . . . . . . . . 136

12 Regression Models for Count Data $\ldots \ldots \ldots \ldots \ldots \ldots \ldots \ldots \ldots$

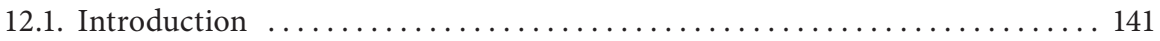

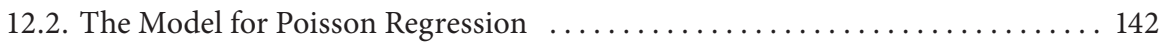

12.3. An Experimental Study of Cellular Differentiation .................. 145 
13 Proportional Hazards Regression $\ldots \ldots \ldots \ldots \ldots \ldots \ldots \ldots \ldots$

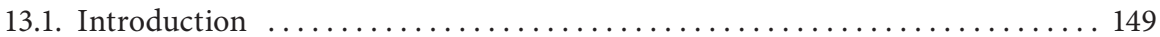

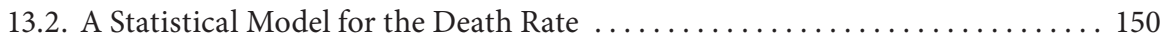

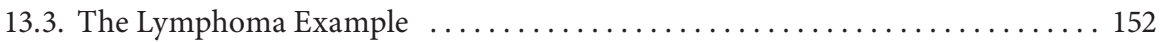

13.4. The Use of Time-Dependent Covariates $\ldots \ldots \ldots \ldots \ldots \ldots \ldots \ldots \ldots \ldots \ldots \ldots \ldots \ldots$

14 The Analysis of Longitudinal Data $\ldots \ldots \ldots \ldots \ldots \ldots \ldots \ldots \ldots \ldots \ldots$

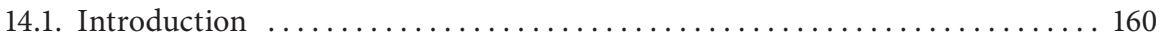

14.2. Liang-Zeger Regression Models ............................ 161

14.3. Random Effects Models ................................... 164

14.4. Multi-State Models ...................................... 167

15 Analysis of Variance . . . . . . . . . . . . . . . . . . . . . 174

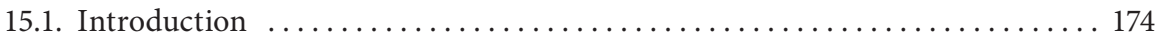

15.2. Representing Categorical Information in Regression Models . . . . . . . . . 175

15.3. Understanding Two-Factor Interactions $\ldots \ldots \ldots \ldots \ldots \ldots \ldots \ldots \ldots \ldots \ldots \ldots \ldots$

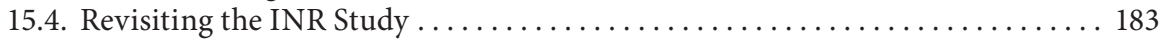

16 Data Analysis . . . . . . . . . . . . . . . . . . . . . . . 191

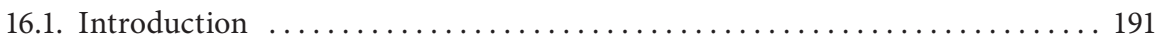

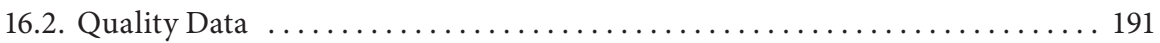

16.3. Initial or Exploratory Analysis . . . . . . . . . . . . . . . . . . . 193

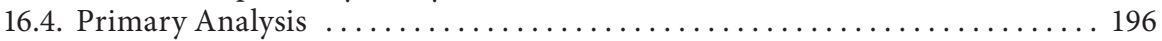

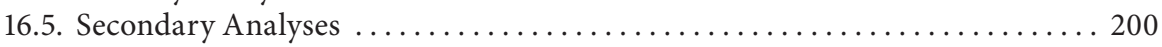

16.6. A Formal Discussion of Multiple Comparisons . ................. 202

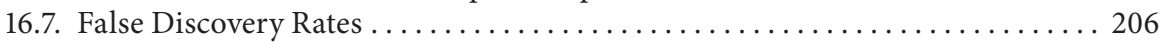

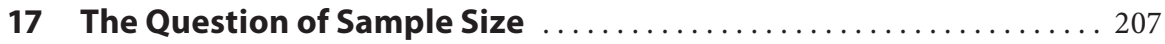

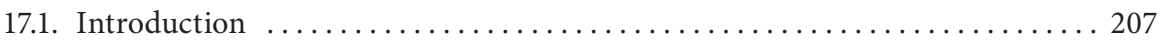

17.2. General Aspects of Sample Size Calculations .................... 207

17.3. Two Examples of Sample Size Calculations . . . . . . . . . . . . . . . . 211

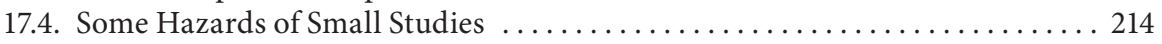

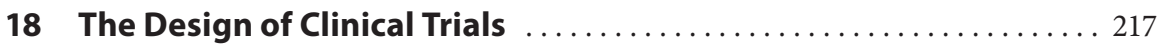

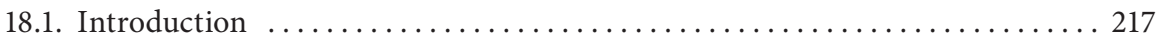

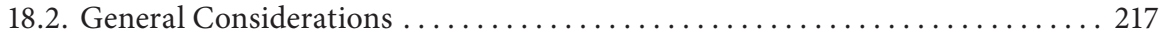

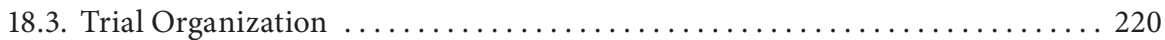

18.4. Randomized versus Historical Controls .......................... 222

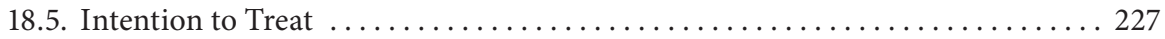

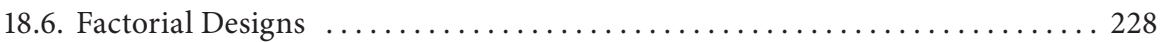

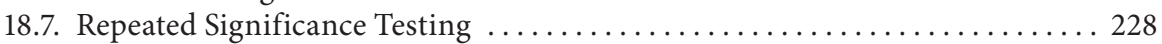

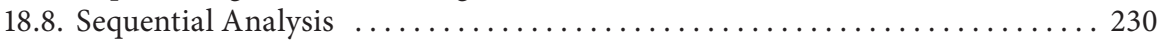

19 Further Comments Regarding Clinical Trials .............. 234

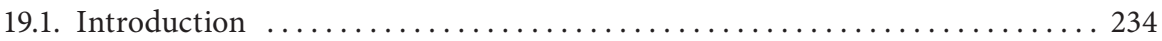

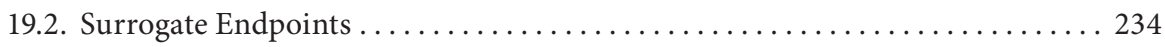

$\begin{array}{llll}\text { Contents } & \text { VIII }\end{array}$ 


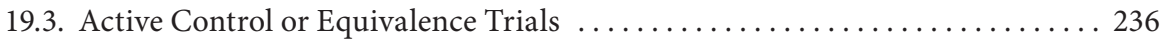

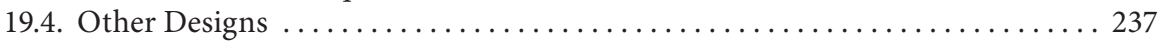

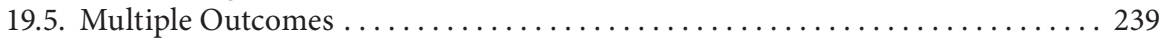

19.6. Multiple Treatment Arms .................................. 242

19.7. Sequential Designs for Efficacy-Toxicity Trials . . . . . . . . . . . . . . 244

19.8. Stochastic Curtailment ................................. 250

20 Meta-Analysis ...................................... 254

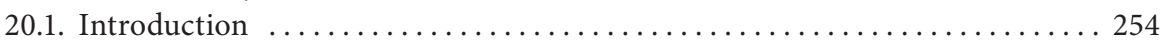

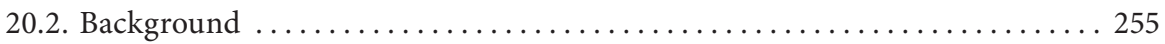

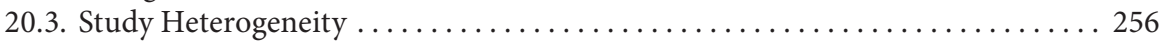

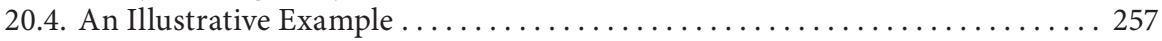

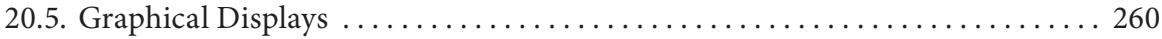

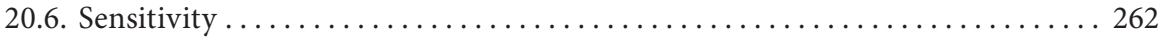

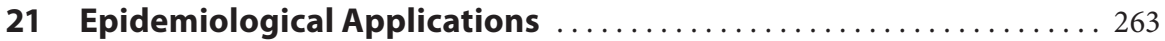

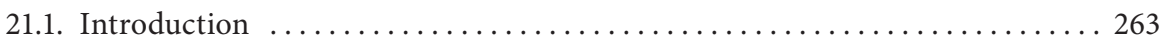

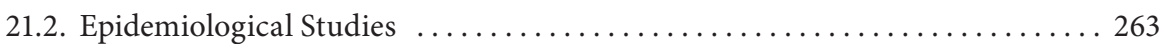

21.3. Relative Risk Models .................................... 264

21.4. Odds Ratio Models ....................................... 268

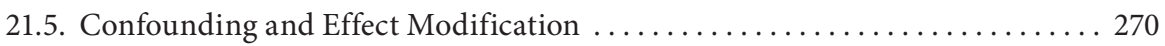

21.6. Mantel-Haenszel Methodology ........................... 273

21.7. Poisson Regression Models .................................... 275

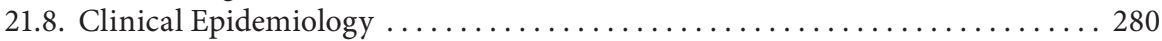

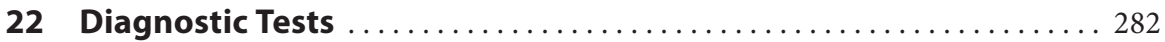

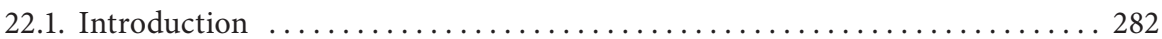

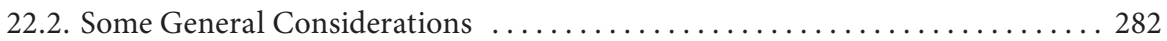

22.3. Sensitivity, Specificity, and Post-Test Probabilities ................ 286

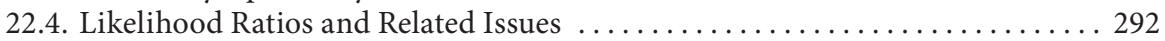

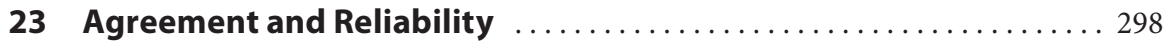

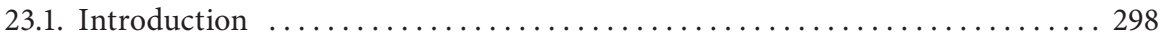

23.2. Intraclass Correlation Coefficient .......................... 300

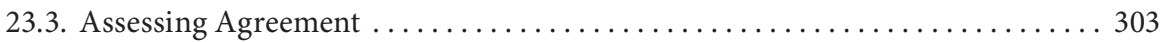

23.4. The Kappa Coefficient ...................................... 304

23.5. Weighted Kappa ....................................... 306

23.6. Measures of Agreement for Discrete Data ...................... 307

23.7. The Dependence of $\kappa$ on Prevalence ............................... 308

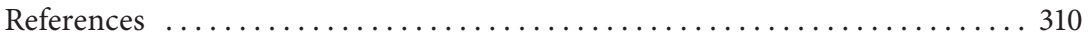

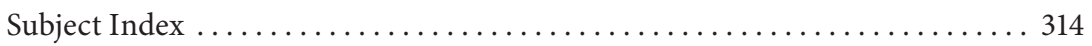

$\begin{array}{ll}\text { Contents } & \text { IX }\end{array}$ 


\section{Preface to the Fourth Edition}

Twenty-five years have elapsed since we first began drafting our thoughts about using and understanding the statistical methods commonly employed in medical research. In the meantime, AIDS, SARS and avian flu, to name only three public health concerns, have burst onto the world stage. So, too, have fears of terrorism, the consequences of global warming and the next pandemic. Communication has been transformed, not least through the development of the World Wide Web. Twenty-five years ago, it would have required remarkable prescience to foretell, even in the vaguest of terms, how circumstances and events would unfold.

Even to predict the changes in attitudes that have occurred concerning smoking in public places, and the dangers of unprotected, excessive exposure to sunlight might have seemed highly speculative when Using and Understanding Medical Statistics first appeared in print.From the perspective of our goals in conceiving the first edition, the fairly widespread adoption of the phrase 'evidence-based medicine' is particularly noteworthy. It implicitly reflects the increased understanding, by physicians, that a basic grasp of statistical concepts and a passing appreciation for what statistical analysis can and cannot do is essential if one wants to be able to read and evaluate the medical literature.

When the first edition appeared, we hoped to make a small contribution to such effective use of the medical literature. Never in our wildest dreams did we imagine that four editions would be published in English, as well as foreign language editions in Italian, Spanish and in Japanese. And when we first began writing, we certainly did not anticipate the topics that would become commonplace in the medical research literature, and which we might therefore feel were appropriate to try and explain to our readers. 
How does this edition differ from its predecessor? In our opinion, the fourth edition represents the most substantial revision of Using and Understanding Medical Statistics since the book was first published in 1984. As medical research has evolved, the statistical methods that are used to sift study data and adduce convincing evidence of improvement and innovation have become increasingly sophisticated. As a result, we have added entirely new chapters on Poisson regression, the analysis of variance, meta-analysis, diagnostic tests and the subject of measurement agreement and reliability. In addition, there are sections describing new topics in the chapters on longitudinal studies, data analysis, and clinical trials. Because statistical software is now widely available, we have removed the nine pages of statistical tables pertaining to Fisher's exact test; there are now many computational tools that will evaluate the exact significance level of this widely-used hypothesis test. Since there is now a chapter describing Poisson regression, we have also been able to add a new section to the chapter on epidemiological applications, one that describes the use of this tool to analyze the classic cohort study of smoking and coronary mortality reported by Doll and Hill. The changes in the public attitude towards smoking to which we previously referred are in large measure due to the pioneering efforts of Drs. Doll and Hill, and their work provides an outstanding example of fruitful collaboration between medical and statistical scientists. Finally, we must admit that the goal we identified in the first edition to have most chapters represent a single evening's reading has proved increasingly difficult to achieve.

First drafts of most of this new material were developed last year while DEM was an antipodean sabbaticant in the Centre for Clinical Epidemiology and Biostatistics at the University of Newcastle, and VTF made use of the excellent research facilities of his employer, the MRC Biostatistics Unit in Cambridge, England. We want to thank the Director and staff of the Centre - and particularly Professor Robert W. Gibberd - for generously providing DEM with a quiet office, as well as access to library and computing facilities. We also thank Professor Simon G. Thompson, the Director of the Biostatistics Unit, and the Unit staff for their support of VTF's efforts. Although the authors were half a world apart, the tangible encouragement of colleagues made writing and collaboration on a first draft of the fourth edition relatively easy.

Thanks are also due to our publisher, S. Karger AG in Basel, and especially to Rolf Steinebrunner, in production management, and Ms. Deborah Lautenschlager with whom we worked on this edition. We are particularly grateful to Rolf who has overseen the publication of all four editions of the book, and plans to retire at the end of 2006. It has been our privilege to enjoy such a long and fruitful relationship with Rolf, and everyone at Karger who has participated in publishing Using and Understanding Medical Statistics. We hope 
Rolf's retirement years will be as fulfilling, and enjoyable, as his working career at Karger seems to us to have been.

For both of us, this year, 2006, marks significant anniversaries of our weddings. In recognition of those pivotal events in our personal lives, once again we dedicate whatever our efforts may have achieved to the two special individuals whose love and support have sustained and enriched our lives for more than half a century of unforgettable, shared experience.

D.E. Matthews V.T. Farewell 


\section{Preface to the Third Edition}

The world today is a very different place from what it was 12 years ago. Setting aside all the political changes that have occurred since Using and Understanding Medical Statistics was first published, there have been extraordinary developments in computing technology that have affected both the practice of medicine and the statistical methods that researchers use to evaluate medical progress. We will leave it to you, the readers of this book, to reflect on how medical practice has changed. From the statistical perspective, consider that when the first edition was published, access to statistical packages that would fit relative risk regression models to survival data was somewhat limited. More often than not, use of this software would have required the assistance of a statistician familiar with the input-output quirks and other vagaries of the routines. Now, the same models are a standard feature of many commercial software packages. Data input is often accomplished using spreadsheet editors, and most of the key aspects of model selection and fitting can be carried out by simply clicking the mouse on the correct item in a pull-down menu. Seconds later, the results of the analysis scroll across the screen. Perhaps the most astonishing aspect of this revolution in statistical analysis is the fact that one can carry out such analyses virtually anywhere - sitting in an airplane, riding on a train, or logged in from an office on one continent to a remote machine halfway round the globe.

The ease with which statistical analyses can now be carried out makes the focus of this book all the more important. Readers of the medical literature in former times may well have thought that a statistically significant result was, perhaps, the primary determinant in the editorial process of selection and publication. However, it has not been, and is not, sufficient simply to carry out some statistical analysis of medical data with this goal in mind. 
Now that complex statistical analyses are easy to execute, it is particularly important that the focus for medical researchers shifts from computation to interpretation and understanding. Readers of the medical journals, now more than ever, need the ability to read and critically appraise the results of various studies that deal with issues in the practice of medicine such as new treatments for a specific disease, the natural history of conditions such as AIDS, or the public health benefit of a new screening program for breast or prostate cancer.

What is different about the third edition of Using and Understanding Medical Statistics? First, there are two new chapters. One of these provides readers with an introduction to the analysis of longitudinal data. We describe two quite different approaches to the analysis of such studies; both methods are beginning to find their way into the mainstream of medical literature. The second new chapter augments material concerning the design of clinical trials that appeared in the first and second editions. Readers are introduced to topics such as the use of surrogate markers, multiple outcomes, equivalence trials, and the design of efficacy-toxicity studies.

In addition to these new chapters, we have reorganized the last third of the book so that the actual order in which topics are introduced precedes their routine use. In this respect the second edition contained one glaring pedagogical error that we are pleased to have the opportunity to rectify. As well, we have taken great pains to carefully re-phrase sentences and paragraphs that did not stand up to scrutiny. We were greatly assisted in this exercise by a Danish medical statistician, Dr. Jørgen Hilden, who sent us several pages of constructive remarks that revealed deficiencies in the second edition. We, and our readers, owe Dr. Hilden a substantial debt of gratitude for this generous exercise of his experience, insight, and labour.

We conclude with one final observation concerning the impact of technological change on normal patterns of work. When the first edition was being prepared, Mrs. Joy Hoggarth typed the manuscript for us, and did a superb job. The second edition was typeset by Ms Lynda Clarke, whose productivity at the keyboard was astonishing. Now both of us write directly onto computers or Xterminals that occupy a corner of the desk, so we have no one to thank for capably assisting us in the preparation of the manuscript for the third edition. On the other hand, we are pleased to say that no technological change prevents us from dedicating this third edition to the same very special people to whom the first and second editions were also dedicated.

D.E. Matthews V.T. Farewell 


\section{Preface to the Second Edition}

Slightly less than four years have elapsed since the preface to the first edition was written. In the meantime, we have been surprised, and pleased, by the response to the first edition. The letters and comments which we have received from readers and reviewers on several continents have brought us much satisfaction. Suggestions and criticisms have helped us to understand specific topics where the first edition failed to meet the goals which we had established. Despite our best intentions, there were inevitable errors in the first edition which we were anxious to correct. Consequently, when the publisher inquired about the possibility of a revised edition, we realized that it would be an opportunity to rectify both kinds of flaws simultaneously.

How do the two editions differ? Apart from minor corrections to Table 3.4 and the elimination of errors which appear to be randomly distributed through the chapters, the principal differences may be found in the second half of the book. The example in chapter 10 has been changed to one which we believe suits better the purpose we intend to achieve. Sections have been added to chapters 11, 12 and 14 which treat topics that were previously omitted. In some ways, these additions reflect the changing face of medical statistics, and the clinical investigations in which statistical methods play an important role. However, the major difference between the editions is the addition of chapter 16, which concerns epidemiological studies. The topics treated in the final chapter illustrate just how much the use of sophisticated statistical analysis has permeated the recent practice of epidemiology. At the same time, this new chapter knits together the fabric of the book, drawing on methods which we have introduced in previous chapters to analyze data from various epidemiological studies. In that respect, chapter 16 does what no chapter in the first edition was able to do. We hope its inclusion in the second edition will help all 
readers, even those whose main interest is not directed towards epidemiology, to integrate their understanding and extend their appreciation for the use of statistical methods in medical research.

We are grateful to Ms Lynda Clarke in the Department of Statistics and Actuarial Science at the University of Waterloo. Her skill and cheerful cooperation made light work of all our changes in the process of preparing the revised manuscript.

D.E. Matthews V.T. Farewell 


\section{Preface to the First Edition}

The origins of this book can be traced to a short course which was offered in the autumn of 1980 to medical researchers at the Fred Hutchinson Cancer Research Center. The syllabus for that course was drawn up to meet the specific needs of those researchers. After re-examining the material we had presented, we felt that the content of the course and the approach we had adopted were different from their counterparts in familiar introductory books on statistics, even those which were written specifically for medical researchers. Unsolicited comments from course participants encouraged us to develop and expand our approach instead of filing the assorted tables and handouts. And so, through additions, deletions and numerous revisions, the final product haltingly took shape and assumed its present form.

Our aim now, as in 1980, is quite simple: to describe the statistical methodology which frequently is found in published medical research, particularly those papers concerned with chronic diseases. This presentation introduces, in some detail, fundamental statistical notions which are common to nearly every method of analyzing data - for example, significance tests. From these foundations we direct our attention to more advanced methods of analysis. In order to avoid excessive complexity in the initial chapters, we rely on the promise of bigger and better things to come to motivate the selected topics we choose to discuss. Nonetheless, there is sufficient introductory detail that we feel obliged to ask our readers to exercise more patience and endurance than most introductions to medical statistics require. We are convinced that solid beginnings are essential to any useful discussion of the important, more advanced methodology which frequently is used in modern medical research.

We have written for the motivated reader who is willing to invest a little time and effort in understanding statistical methods. On the other hand, our 
constant goal has been to write a book which could be read fairly easily in installments. We hope that most chapters represent a single evening's reading. Although one might decide to devote a little more time to some of the details, it should then be possible to tackle the next chapter. We shall be pleased if we have succeeded in achieving this goal; however, we do not wish to be regarded as competing with alternative evening reading which may be more interesting or exciting!

Except, perhaps, for an over-emphasis on chronic diseases, we believe that a medical student who understands the contents of this book will be well-informed regarding medical statistics. Whether medical students, who often regard statistics as an unnecessary evil, should and can be adequately motivated to master this material is an open question. We have not attempted to provide this motivation ourselves. In our view, the most persuasive arguments on behalf of the subject will always be those advanced by medical researchers who have themselves established a use for statistical analysis which does not depend on the editorial policy of medical journals.

The final preparation of this manuscript took place while one of us (V.F.) was visiting the Department of Biomathematics at the University of Oxford, and the other (D.M.) was visiting the Department of Medical Statistics and Epidemiology at the London School of Hygiene and Tropical Medicine. We want to thank Professors Peter Armitage and Michael Healy for making these visits possible. We are also greatly indebted to Mrs. Joy Hoggarth at the Fred Hutchinson Cancer Research Center for her superb preparation of the manuscript. She was greatly handicapped by being more than 5,000 miles from the authors.

An early version of this book was read by Dr. G.J. D'Angio of the Children's Hospital of Philadelphia; his helpful comments and criticisms had a significant influence on the final manuscript. We thank him for this and, in general, for his unwavering support of statistics in medical research. It is our hope that this book will help other investigators to develop a similar appreciation for the value of medical statistics.

D.E. Matthews

V.T. Farewell 